\title{
Application of Visual Sensing Image Processing Technology under Digital Twins to the Intelligent Logistics System
}

\author{
Jianjun Miao ${ }^{1}$ and Shundong Lan (iD ${ }^{1,2}$ \\ ${ }^{1}$ College of Economics and Management, Nanjing University of Aeronautics and Astronautics, Nanjing 210016, China \\ ${ }^{2}$ School of Economics and Management, Hubei University of Arts and Science, Xiangyang, Hubei 441053, China \\ Correspondence should be addressed to Shundong Lan; 11076@hbuas.edu.cn
}

Received 10 October 2021; Accepted 12 November 2021; Published 24 December 2021

Academic Editor: Zhihan Lv

Copyright ( 92021 Jianjun Miao and Shundong Lan. This is an open access article distributed under the Creative Commons Attribution License, which permits unrestricted use, distribution, and reproduction in any medium, provided the original work is properly cited.

Since the founding of the People's Republic of China, the advantages of logistics are neglected, and the scale operation and the welfare in the industry are difficult to achieve due to the influence of the economic system and social environment. Therefore, a new intelligent logistics distribution management system based on machine vision and visual sensor image processing technology is constructed to respond to the shortcomings of the traditional system, including slow efficiency, huge cost, complex data, and low degree of informatization. Through the analysis and research on the visual sensor image processing technology and the order processing, receipt management, distribution management, scheduling management, and return management that affect logistics distribution, a simulation experiment is used to verify that the visual sensor image processing technology is rigorous, intelligent, and efficient and has high precision. The intelligent logistics distribution management system can effectively solve the problems existing in the traditional logistics distribution management. The experimental results show that the visual sensor image processing technology can collect and analyze the target image and effectively track and monitor it in the logistics distribution process. The average distribution precision of the intelligent logistics distribution management system reaches more than $99.5 \%$, which is greatly improved compared with $90 \%$ of the traditional logistics distribution. And it can greatly improve the distribution efficiency, which increases by about $26.5 \%$. The study realizes the information management of the logistics system and automatically completes all the work according to the designed program, so that the real-time dynamic distribution can be transmitted to the urban logistics distribution at any time.

\section{Introduction}

Logistics management is called the "third profit source" of modern society, and it is reflected in the potential and economic benefits of logistics systems [1]. With the proposal of "Made in China 2025" and "Industry 4.0", China's industrial structure gradually shifts to intelligent informatization $[2,3]$. The development of e-commerce promotes the prosperity of logistics distribution and prompts more and more people to engage in the logistics distribution industry. However, due to the development of the logistics distribution industry, the number of data generated is becoming increasingly huge. The traditional manual method usually causes data confusion and loss, increases the workload, and reduces work efficiency. The problem of "inefficient and high consumption" in the logistics distribution industry gradually becomes a bottleneck restricting the development of the industry. Reducing logistics distribution costs and improving logistics distribution services and logistics distribution efficiency pose a challenge to the current logistics distribution system $[4,5]$.

Therefore, constructing an intelligent logistics distribution management system becomes necessary and urgent [6]. In this case, an intelligent logistics distribution management system based on machine vision can update the traditional logistics distribution system, and it can promote the all-around development of the current logistics distribution system and help it develop intelligently [7]. Sternberg and Norrman [8] analyzed scientific papers, project reports, specifications, and other publications 
related to The Physical Internet (PI) to help researchers and decision makers develop efficient logistics systems, and PI is tested based on four factors, namely organizational readiness (technical blueprint), external pressure (commitment effect), perceived benefits (business model), and adoption. Liu et al. [9] applied collaborative business intelligence systems to hospital supply, processing, and distribution logistics management models. The business process theory is improved by using data mining technology to identify knowledge and collaborative technology from complex data. For the application of the system, a hierarchical collaborative system is proposed for the intelligent management of hospital logistics, and a database for the collaborative system is established. Yang and $\mathrm{Wu}$ [10] discussed the vehicle routing and its extension and introduced the ant colony algorithm, focusing on the principle of the ant colony algorithm, to improve the ant colony algorithm, so that the problems in vehicle routing can be solved. The results show that the improved algorithm can improve the efficiency of logistics transportation, reduce transportation costs, and increases economic benefits. The development of Internet technology promotes the development of intelligent logistics distribution management system. More and more new technologies are gradually applied to the intelligent logistics distribution management system. Sensor technology and sensor networks are widely used in target recognition in the logistics distribution system.

Based on visual sensor image processing technology and intelligent management, DTs are used to manage the distribution process efficiently, and the "black box" mode is transparent. And an efficient, high-quality, low-cost intelligent logistics distribution management system is built to realize the integration, agility, automation, visualization, and specialization of the logistics distribution management system. The innovation is to construct a new intelligent logistics distribution management system based on visual sensor image processing technology through the analysis and research on the visual sensor image processing technology, order management, receiving management, distribution management, scheduling management, and return management that affect the logistics distribution. The demand, functional elements, operation process, and data flow of the distribution center system are analyzed according to the principle of software engineering. The overall architecture of the urban logistics distribution system is designed, the functional levels and main functional modules of the system are analyzed, and the system database is established.

\section{Materials and Methods}

\subsection{Analysis of Relevant Concepts}

2.1.1. Machine Vision. Machine vision is a new technology developed based on artificial intelligence (AI), and it uses machine observation to replace human eyes to identify, measure, and judge things. It combines optical imaging, image processing, sensors, digital simulation, computer technology, and mechanical engineering technology together [11]. In real life, the objective model is created to identify and obtain the target image and complete the observation and analysis of practical problems. And the application of robots is expanded, and the microscopic and macroscopic visions of things are developed [12]. The machine vision system has the characteristics of high flexibility and strong automation and is usually used to identify things in extreme working environments and scenes, which is difficult to do by human eyes.

The classical machine vision system is generally composed of a light source system module, an image capture module, a digitization module, a digital image processing module, an image intelligent judgment decision module, and a mechanical control execution module. First, the machine vision system captures and converts the target image by using the image recognition shooting device and sends the converted image signal to the dedicated image processing system, obtaining the basic morphological characteristics of the target. Second, the target color, brightness, pixel distribution, and other information are digitized, and the digitized image is processed to obtain the significant characteristics of the target. Finally, the field equipment is controlled to achieve the existing purpose according to the results of the intelligent discriminant decision. The optical sensing equipment used in the process includes the complementary metal-oxide-semiconductor (CMOS) and the charge coupled device (CCD). The device can realize the automatic acquisition of the target image and analyze the target image to obtain the morphological information of the target object, making judgments and decisions and realizing the control of the target image $[13,14]$. The structure of the machine vision system is shown in Figure 1.

2.1.2. Intelligent Logistics. Intelligent logistics is based on the current intelligent integrated system. The existing sensors, bar code, radio frequency identification, and global positioning and other more advanced technical means of logistics industry involved in packaging, warehousing, transportation, distribution, and handling links are used to make the logistics system simulate human intelligence. After that, the system has the ability to think, perceive, learn, and solve problems. Intelligent logistics is automatic and efficient, and it can reduce freight costs and resource consumption and improve service levels [15]. In freight transportation, intelligent logistics should ensure six "exactness", namely, exact goods, quantity, location, quality, time, and price. And it should also perform the identification, tracking, traceability, monitoring, and real-time response of goods. Because of the impact of economic globalization on transport costs, the competition in the logistics industry is increasingly fierce, and the rational allocation of resources and effective cost control attract much attention. The development of science and technology and the rise of the network make intelligent logistics an effective means to reduce the cost of enterprises, improve their service quality, and enhance their competitiveness [16]. Under the requirements of the new era, intelligent logistics gradually becomes a system with intelligence, 


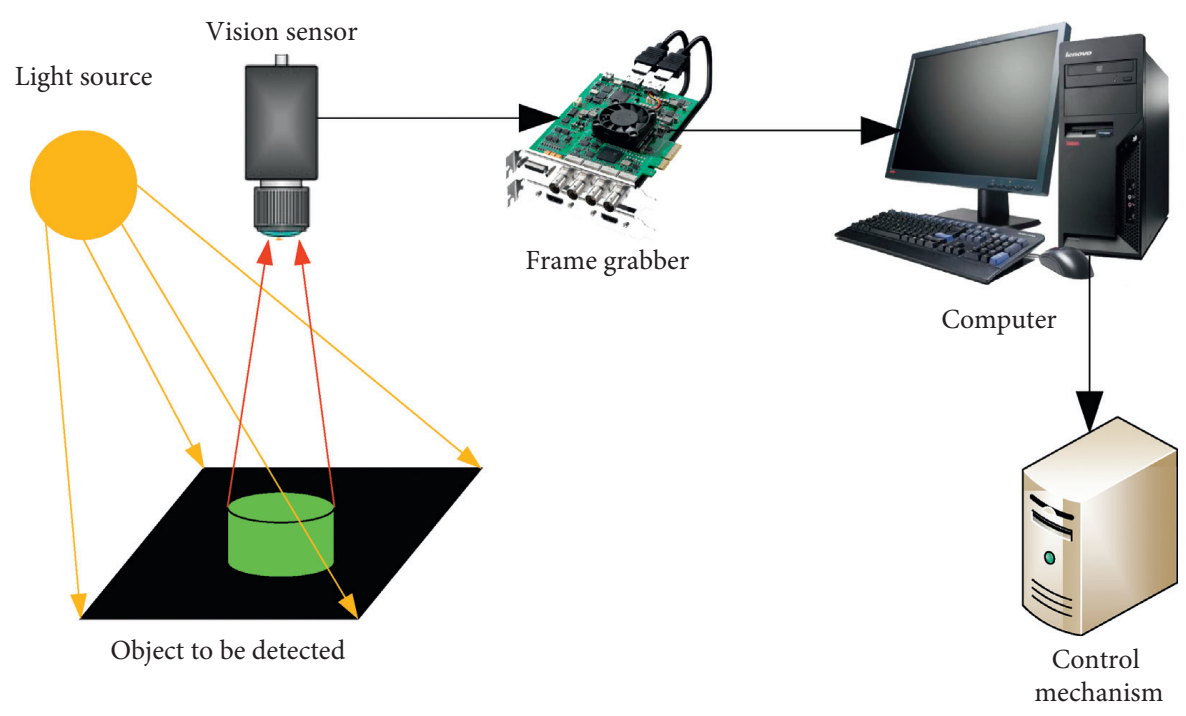

Figure 1: Composition of the machine vision system.

informatization, environmental protection, industrial synergy, globalization, and internationalization. Intelligent logistics has the characteristics of intelligence, integration, hierarchy, flexibility, and socialization, which is reflected by intelligent decision-making in the process of freight transportation. The integration and hierarchy of the rational allocation of freight transport links are realized. And resource allocation is carried out according to consumers' demands. The structure of the intelligent logistics system is shown in Figure 2.

The intelligent logistics distribution management system (ILDMS) is based on AI, network information technology, and the intelligent transportation system (ITS). It collects real-time data in the process of logistics distribution, analyzes and processes them, and makes intelligent decisions. And then the high efficiency and low consumption are realized, and detailed information and consulting services for personnel involved in various links are provided. In the intelligent logistics distribution management system, "intelligence" is the core, "ability" is the key, "goods" is the premise, "flow" is the realization, and "distribution" is the organic combination of "distribution" and "delivery". "Intelligence" reflects the efficiency of information perception and decision-making. "Ability" is the fast and effective collaboration, the strong implementation ability, and high automation between various facilities. "Goods" mainly refers to the type, quantity, and quality of goods in the distribution process. "Flow" refers to the flow of goods, and it is also the core transportation link in logistics distribution. In the whole logistics service, "distribution" is the nearest link to the product terminal. How to send the customer's required goods in time under complex road conditions within a period becomes the primary task of the intelligent logistics distribution management system.

2.1.3. DTs. A model of DTs combined with the specific logistics distribution system is proposed based on the fivedimension of DTs and the modeling method, making DTs applied to the specific logistics distribution. The five dimensions are physical distribution operation, virtual distribution operation, the physical distribution service system, the twin data of logistics distribution, and system connection. The model is shown in Figure 3.

\subsection{Target Image Processing Based on Visual Sensor Image Processing Technology}

2.2.1. Visual Sensors. The vision sensor is also known as an intelligent camera. It is an embedded small machine vision system that combines image acquisition, image processing, information transmission, and I/O (Input/Output) control modules. It is also a new technology in the field of machine vision in recent years $[17,18]$. The visual sensor is responsible for capturing and shooting the information of the whole machine vision system. It is generally composed of one or two sensors, and it needs auxiliary equipment, such as optical projectors, to complete the operation. The most important function of the visual sensor is to capture and shoot a large number of original images of the target and complete image processing and analysis [19]. The integrated design of the visual sensor greatly reduces the complexity of the device, improves its reliability, and broadens its application fields. The visual sensor is generally composed of the image acquisition module, the image processing module, the image processing software, the communication device, and the I/O control interface. The visual sensor has the characteristics of high integration and strong functional modularization. It combines the light source, camera, image processor, standard control, and communication interface to realize the fast communication between personal computers (PC) and programmable logic controllers (PLC). As an independent intelligent image acquisition and the processing module, the internal memory of the visual sensor can store the downloaded image processing algorithm [20]. The visual sensor system is shown in Figure 4. 


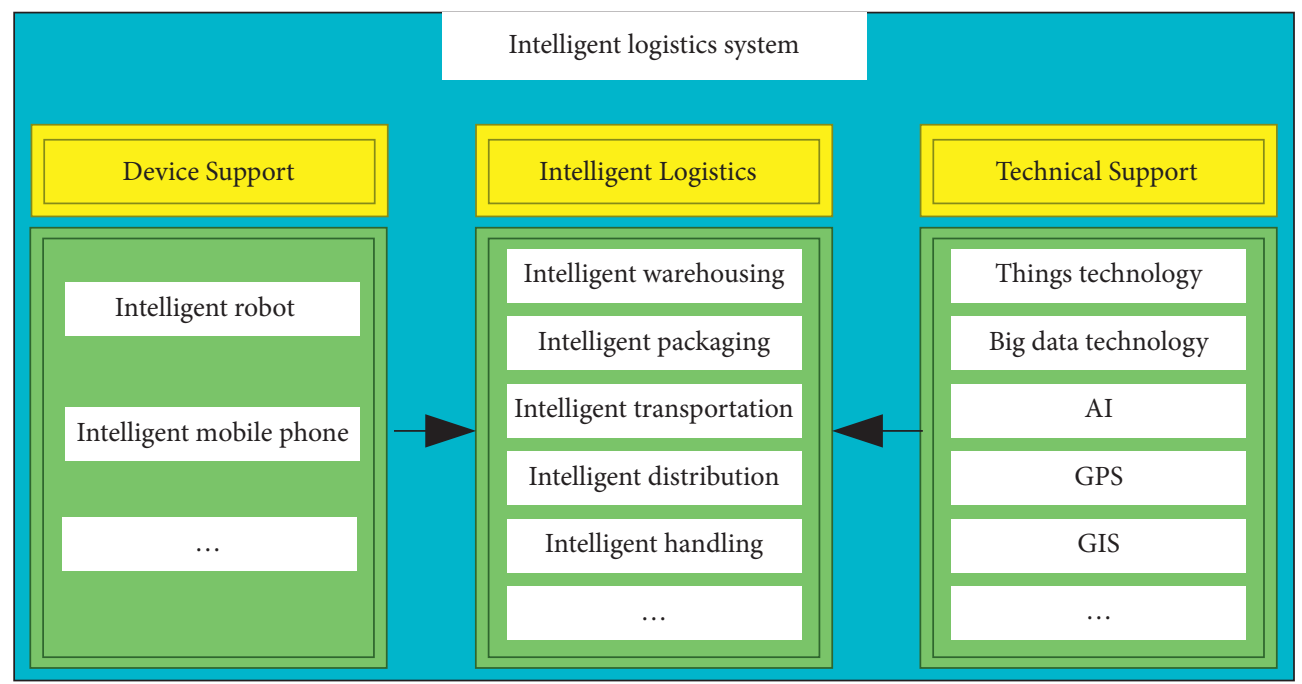

FIGURE 2: Intelligent logistics system.

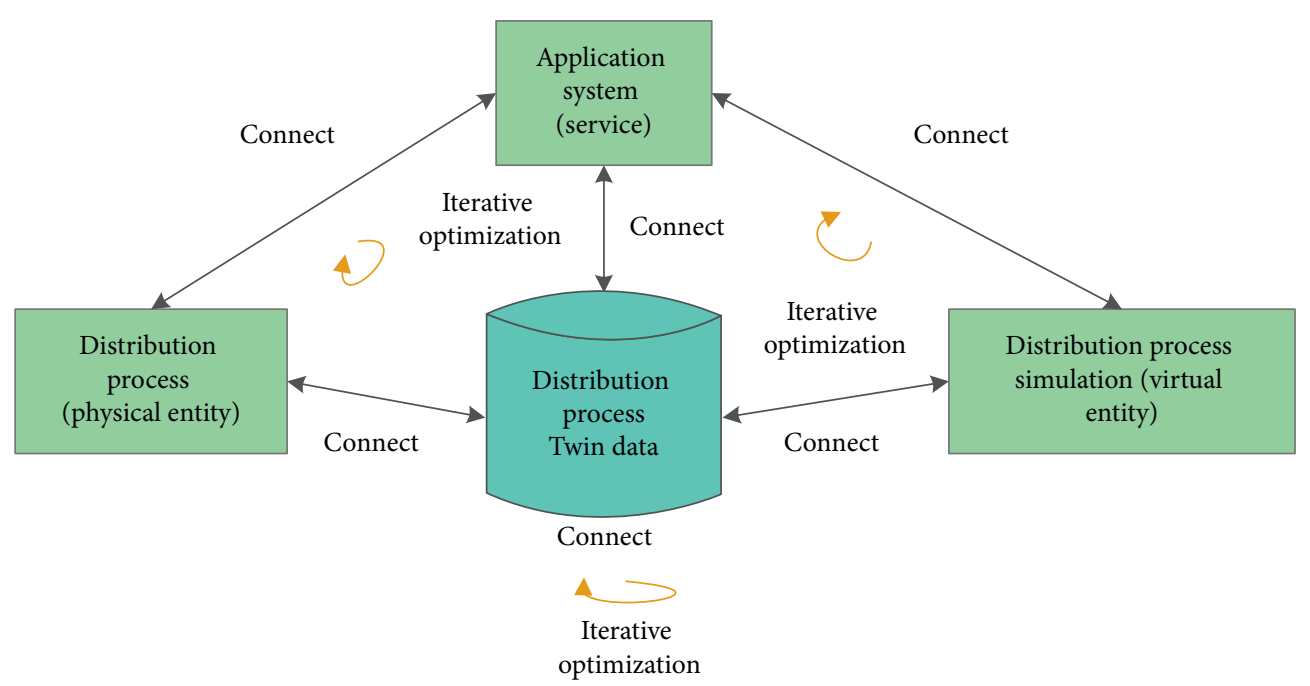

FIGURE 3: DTs five-dimensional model of logistics distribution.

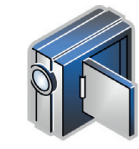

Image acquisition module

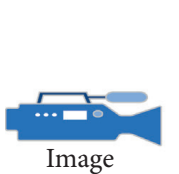

Sensor

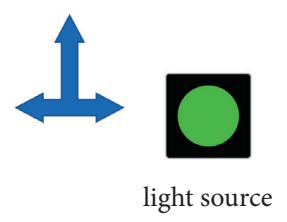

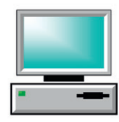

Image processing module

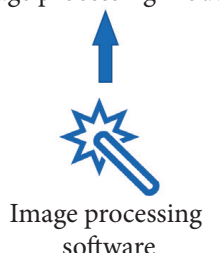

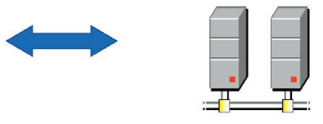

Information transfer module

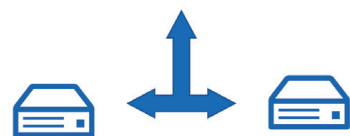

Communication Interface

Figure 4: Composition of the visual sensor system. 
In short, under the increasingly complex situation of the logistics distribution industry, object recognition and detection based on visual sensor image processing technology has high precision, high intelligence, high anti-interference, and simple composition, which meet the requirements of intelligent control in modern logistics distribution. Therefore, the target recognition detection is conducted based on visual sensor image processing technology, hoping to build a more excellent intelligent logistics distribution management system.

2.2.2. Process Analysis of Target Image Processing. In logistics distribution, a large number of images are taken on roads and in an open space. According to image engineering, the target image should be analyzed and processed by three steps, namely image preprocessing, image analysis, and image feature extraction. The image analysis process is shown in Figure 5.

The image enhancement algorithm is as follows:

$$
\bar{f}=1-\left(\frac{f}{M}\right)
$$

In equation (1), the range of gray function $f$ is $[0, M)$. For the image of 8 bit, $M=256$. The simplified algorithm is as follows:

$$
\log \left(\bar{f}^{\prime}(i, j)\right)=\alpha \log (\bar{a}(i, j))+\beta[\log (\bar{f}(i, j))-\log (\bar{a}(i, j))] .
$$

In equation $(2), \bar{f}(i, j)$ and $\bar{f}^{\prime}(i, j)$ are the original and the processed gray functions, respectively, and $\alpha, s$, and $\beta$ are constants.

$$
\log (\bar{a}(i, j))=\frac{1}{n^{2}}\left(\sum_{k=i-n / 2}^{i+n / 2} \sum_{l=j-n / 2}^{j+n / 2} \log (\bar{f}(k . l))\right) .
$$

In equation (3), $\bar{a}(i, j) \in(0,1]$ and $\alpha \log (\bar{a}(i, j))$ can enhance the degree of the image especially in the dark or bright area. The enhanced image $f(i, j)$ can be obtained by substituting $\bar{f}^{\prime}(i, j)$ for $\bar{f}$ to calculate its inverse operation $f=(1-\bar{f}) M$. The above equation can enhance the image details and the noise in the image, so equation (2) can be converted to the following equation.

$$
\log (\bar{f} \prime(i, j))=\log \left(T\left(a^{\prime}(i, j)\right)\right)+\beta_{s}[\log (\bar{f} \prime(i, j)-\log (\bar{a}(i, j)))] .
$$

In the above equation, $\beta_{s}$ is $\beta$ in equation (2) and $T$ is $\alpha$ in equation (2).

$$
\beta_{s}=\beta_{0}\left|I_{g}(x, y)\right| \operatorname{MAXI}_{g}\left(\beta_{0}=3.0\right) .
$$

$I_{g}(x, y)$ is the image gradient and $\mathrm{MAXI}_{g}$ is the maximum image gradient. Its gradient operator is as follows:

$$
\left\{\begin{array}{l}
P_{0}[i, j]=I[i-1, j]-I[i+1, j], \\
P_{45}[i, j]=2 \times(I[i+1, j-1]-I[i-1, j+1]), \\
P_{90}[i, j]=I[i, j-1]-I[i, j+1], \\
P_{135}[i, j]=2 \times I[i-1, j-1]-I[i-1, j+1] .
\end{array}\right.
$$

$P_{0}[i, j]$ is the horizontal partial derivative, $P_{45}[i, j]$ is the partial derivative at the direction of $45^{\circ}, P_{90}[i, j]$ is the vertical partial derivative, and $P_{135}[i, j]$ is the partial derivative at the direction of $135^{\circ}$.

$$
I_{g}(i, j)=\sqrt{P_{0}^{2}[i, j]+P_{45}^{2}[i, j]+P_{90}^{2}[i, j]+P_{135}^{2}[i, j]} .
$$

$I_{g}(x, y)$ is the image gradient. Equation (7) can be simplified as follows:

$$
I_{g}[i, j]=\left|P_{0}[i, j]\right|+\left|P_{45}[i, j]\right|+\left|P_{90}[i, j]\right|+\mid P_{135}[i, j] .
$$

In the above equation, $I_{g}[i, j]$ is the gradient image.

2.2.3. $\mathrm{B} / \mathrm{S}$ Architecture. The $\mathrm{B} / \mathrm{S}$ architecture, namely the Browser/Server architecture, is the continuation and improvement of the traditional $\mathrm{C} / \mathrm{S}$ architecture. In the $\mathrm{B} / \mathrm{S}$ architecture, the server handles various complex business logic, and the browser is responsible for the interaction with users and interface display. The user sends a request to the server through the interface displayed by the browser, and the server receives the user's request and processes it accordingly. Then the results of the user's request are returned to the browser, and all the displayed content on this page is generated by the web browser. The traditional $\mathrm{C} / \mathrm{S}$ architecture is the client/server architecture. It reduces the amount of server computing and network data transmission through the reasonable allocation of data computing and processing on the client and server. The client also has some processing ability. However, it is gradually replaced by $\mathrm{B} / \mathrm{S}$ due to the poor compatibility, poor scalability, and high maintenance.

Compared with $\mathrm{C} / \mathrm{S}, \mathrm{B} / \mathrm{S}$ has the following advantages:

(1) It is convenient and flexible. Users do not need to install any client program on the computer, and just open the browser to access texts, images, videos, and audios. But in $\mathrm{C} / \mathrm{S}$, each client needs to install software. If there are problems in installation, each device needs to be maintained alone, which increases the cost considerably.

(2) It has high compatibility. B/S has the ability to cross platforms. Unlike C/S, users need not care whether their operating system is compatible with software.

(3) It is easy to upgrade and maintain. The upgrading and maintenance of $\mathrm{B} / \mathrm{S}$ architecture are mainly concentrated on the server and all systems can be updated synchronously by changing the web page, while $\mathrm{C} / \mathrm{S}$ cannot be separated and each client must manually install the upgrade system, which costs a lot. 


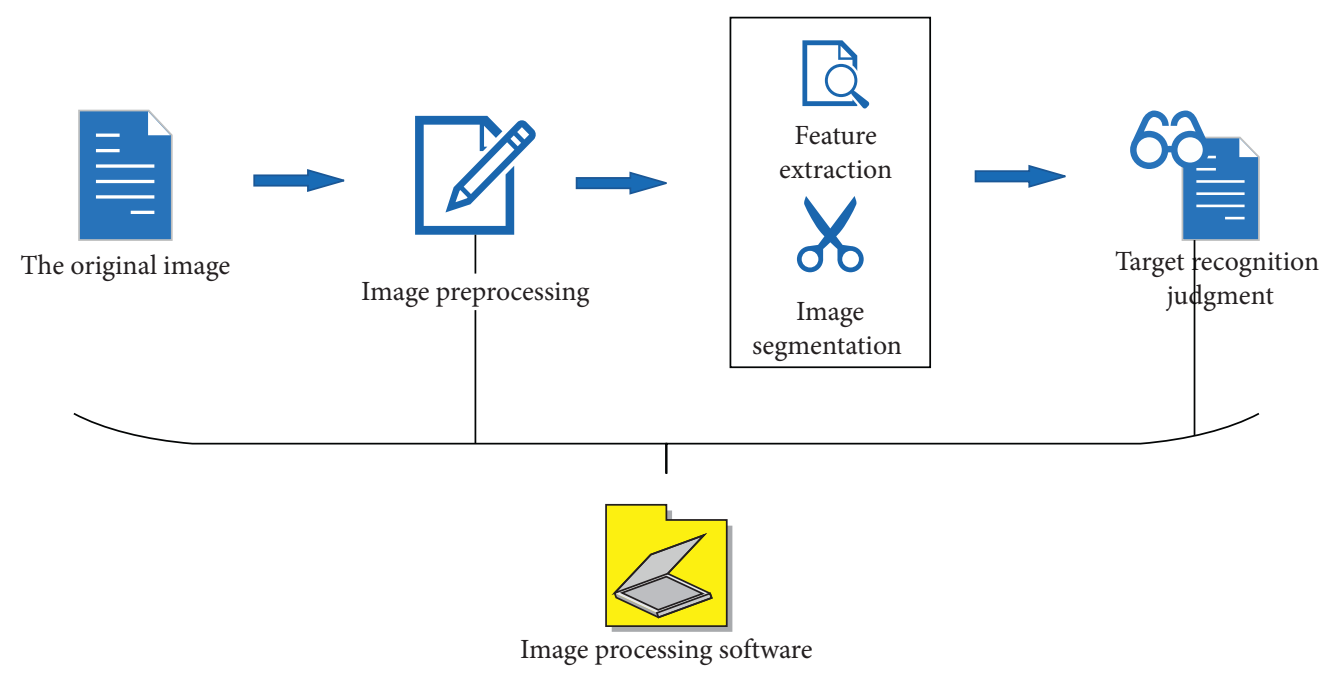

Figure 5: Analysis of target images.

\section{Construction and Analysis of the Intelligent Logistics Distribution Management System Based on Visual Sensor Image Processing Technology}

Distribution management is the top priority in the intelligent logistics distribution management system. How to reasonably optimize the distribution route and scientifically schedule the distribution vehicle in the process of logistics distribution directly affect the efficiency and cost of the whole logistics distribution [21]. Logistics distribution starts from the order and ends when customers receive goods and pay for it. The general process is as follows: the operator receives the order and knows about the relevant information. The system dispatches an appropriate vehicle to collect and load the goods, and the distribution route is planned. Deliverers load goods according to orders and complete distribution according to the planned route. In the process of goods distribution, vehicles and distribution personnel are tracked and managed according to the logistics distribution management system, and logistic information is sent to customers in real time. When customers receive goods, the clerk returns confirmation and cost settlement, and the whole distribution management is completed $[22,23]$. The influencing factors in the distribution management include the number and size of goods, customers' requirements, distribution costs, distribution routes, and distribution modes. Enterprises should make scientific and reasonable decisions on distribution routes and distribution modes, realizing intelligent management of logistics distribution.

\subsection{Requirements for the Functions of the System}

3.1.1. Order Processing. Order processing is performed in the external window of the intelligent logistics distribution management system, and it can be observed by customers directly. It includes order receiving, order auditing, order query, and order data processing. First, the operator should arrange the distribution time and distribution distance and upload them to the database of the system after receiving customers' orders. Second, the system verifies the information of the order to judge whether to accept the order. Then, the operators, distributors, and customers can query the feedback of the system on the orders in real time and know about the order distribution information. Finally, the system responds to the orders promptly and evaluates the delivery cost according to the time, place, distance, weight, and other factors. The process of order processing is shown in Figure 6.

3.1.2. Receipt Management. Receipt management is the most basic and important link in logistics distribution. It includes several parts, namely a receiving plan, a receiving route, and replenishment processing. After receiving the audited information, the salesman sorts the goods to be delivered according to the demand, plans the receiving route, replenishes the source in time, and makes the corresponding replenishment order. The specific process of receipt management is shown in Figure 7.

\subsubsection{Physical Distribution Management (PDM).} Distribution management is the core of the logistics distribution management system, and it includes loading decisions, route decisions, and vehicle scheduling decisions. The intelligent logistics distribution management system makes the loading decision according to the actual situation of the order and sends the generated order to the clerk, who takes the goods from the warehouse. And then the goods are delivered by vehicles. The system optimizes the distribution route according to the real-time road conditions and tracks the distribution in real time. The process of distribution management is shown in Figure 8.

3.1.4. Scheduling Management. Scheduling management refers to scheduling vehicles and dispatchers according to the distribution plan generated by the system and tracking the distribution process. Scheduling management includes 


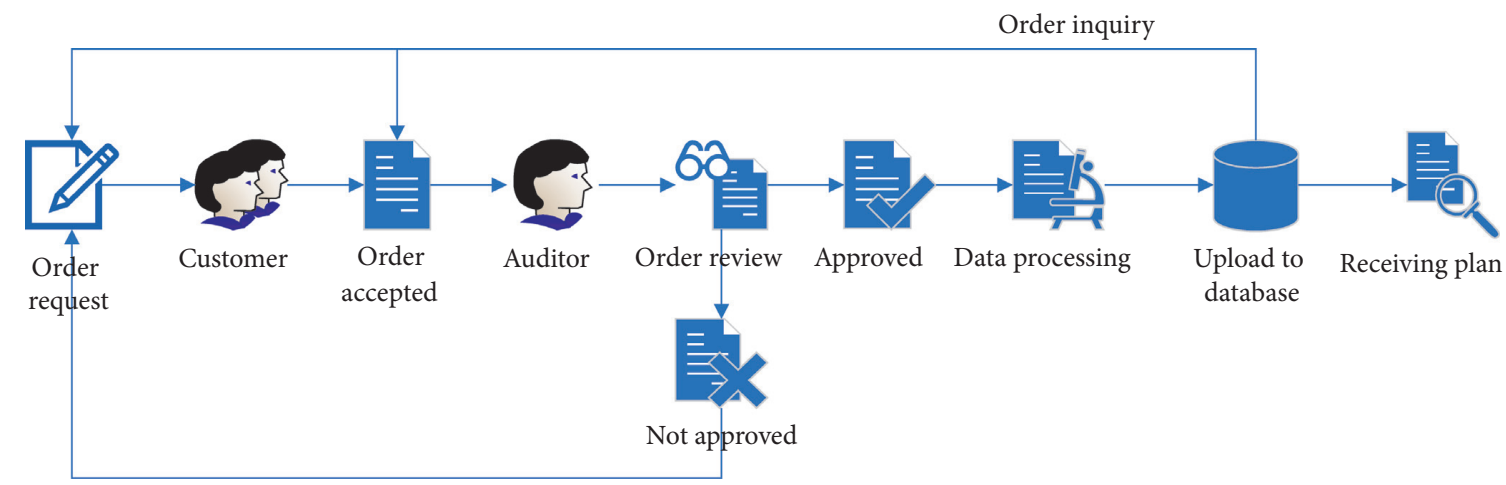

FIGURE 6: Order processing flow.

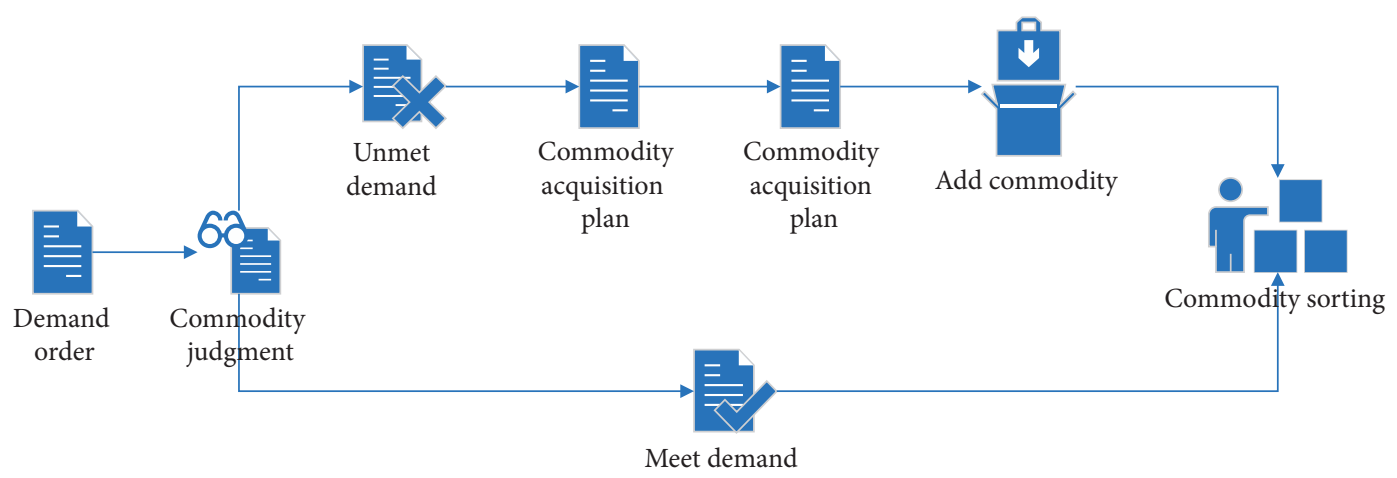

FiguRE 7: Receipt management process.

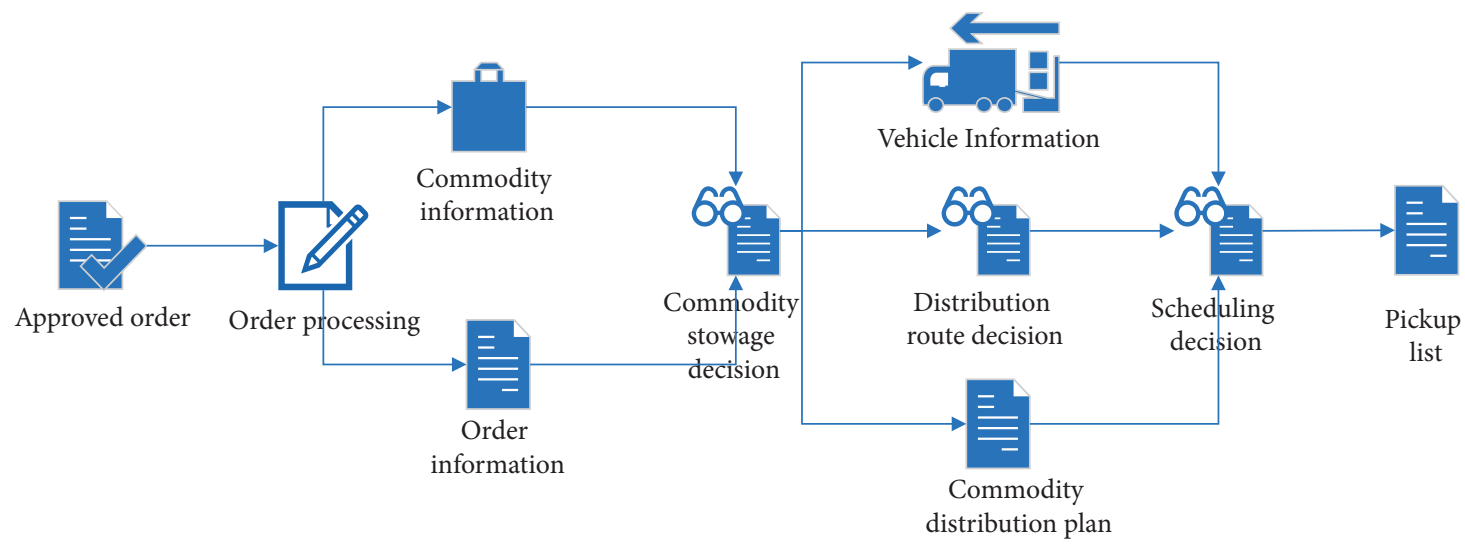

Figure 8: Distribution management process.

vehicle scheduling, dispatcher management, vehicle data management, and distribution tracking management. In the process, the distribution vehicles and distribution personnel are arranged according to the decision, and the real-time state in the distribution process is tracked and supervised by the proper management and maintenance. The specific process of scheduling management is shown in Figure 9.

3.1.5. Return Management. Return management is based on customers' returns, including return entry, return audit, and return sorting. The salesman inputs the customer return into the database in the system as the basis and audits the returned goods. Returns are processed by an audit, and the audit needs to communicate with customers when there are some conflicts. The specific process of return management is shown in Figure 10.

3.2. Construction and Analysis of the Intelligent Logistics Distribution Management System. The intelligent logistics distribution management system uses a geographic 


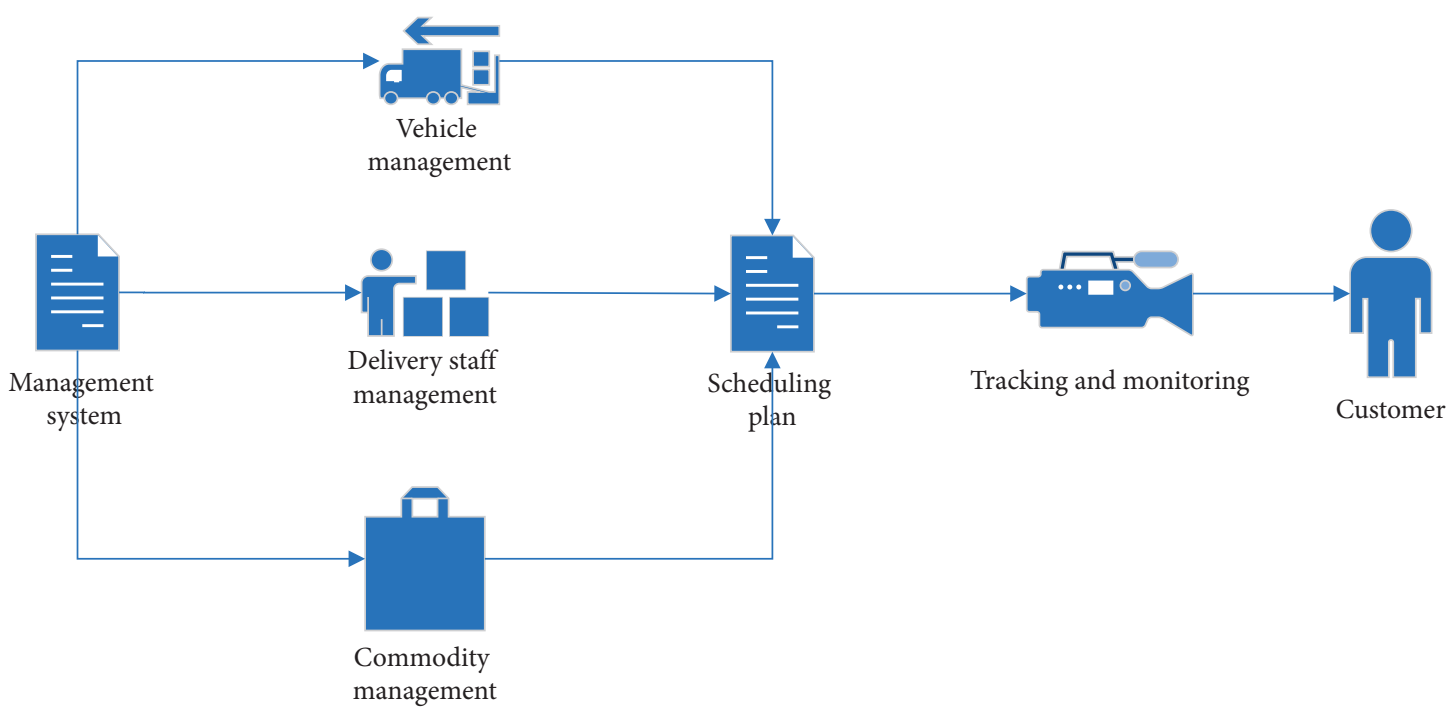

FIgURE 9: Scheduling management process.

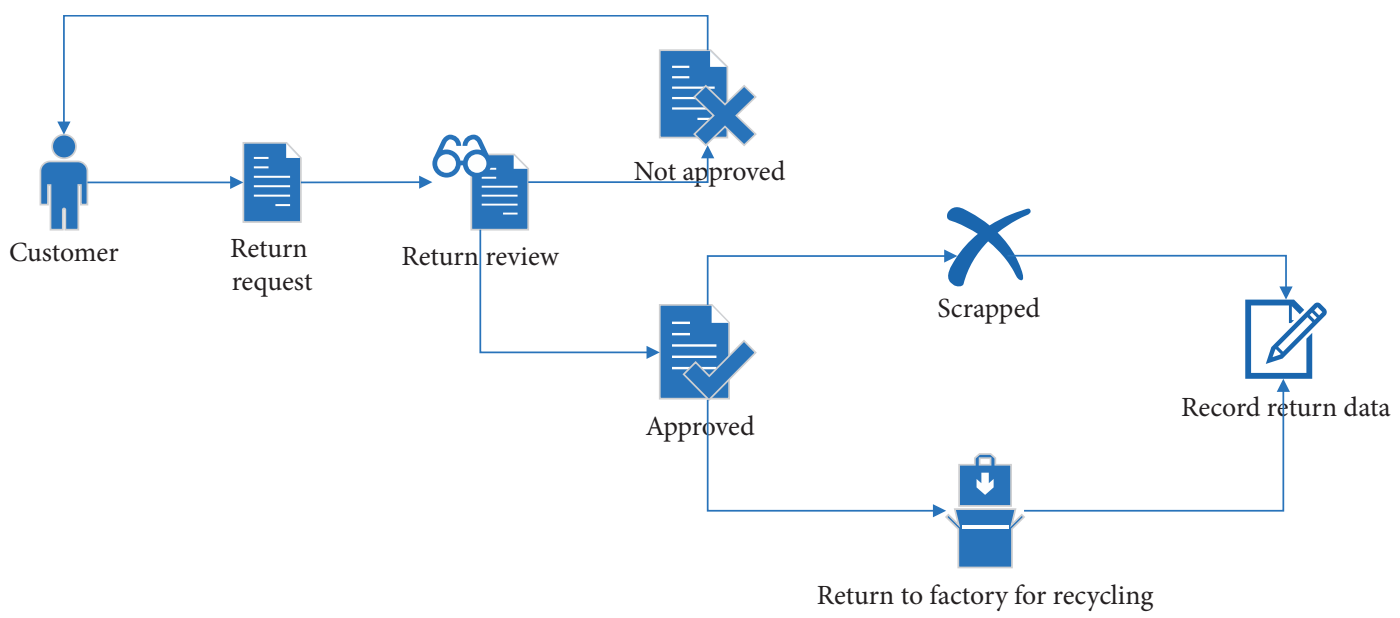

Figure 10: Return management process.

information system (GIS), a global positioning system (GPS), an optimized distribution route, a multiobjective decision-making device, and a high-precision digital map and other advanced technologies to scientifically distribute and schedule orders and vehicles, realizing intelligent distribution. According to the requirements for a wide, diverse, dynamic, and complex intelligent logistics distribution system, Browser/Server $(\mathrm{B} / \mathrm{S})$ is used to construct such a system. The $\mathrm{B} / \mathrm{S}$ architecture is the server and browser architecture, and it is composed of the presentation layer, application layer, and data layer. It has low requirements for computers and simple maintenance procedures [24,25]. The architecture of the system is shown in Figure 11.

A large number of investigations are carried out on the logistics industry, and the procedures involved in logistics distribution should be familiar with. According to the research results and the above framework, an intelligent logistics distribution management system is designed according to distribution management, customer management, and financial management. Among them, distribution management includes basic units, such as information management, order management, scheduling management, distribution management, warehousing management, return management, and report management. The specific structure of the intelligent logistics distribution management system is shown in Figure 12.

\subsection{Simulation Experiment}

3.3.1. Target Recognition Verification Based on Visual Sensor Image Processing Technology. The visual sensor image processing technology is used to identify the vehicle and goods in the process of intelligent logistics distribution. The collected images are analyzed and processed by using the image filtering algorithm and the image segmentation algorithm, and the practical value is verified by analysis and comparison. 


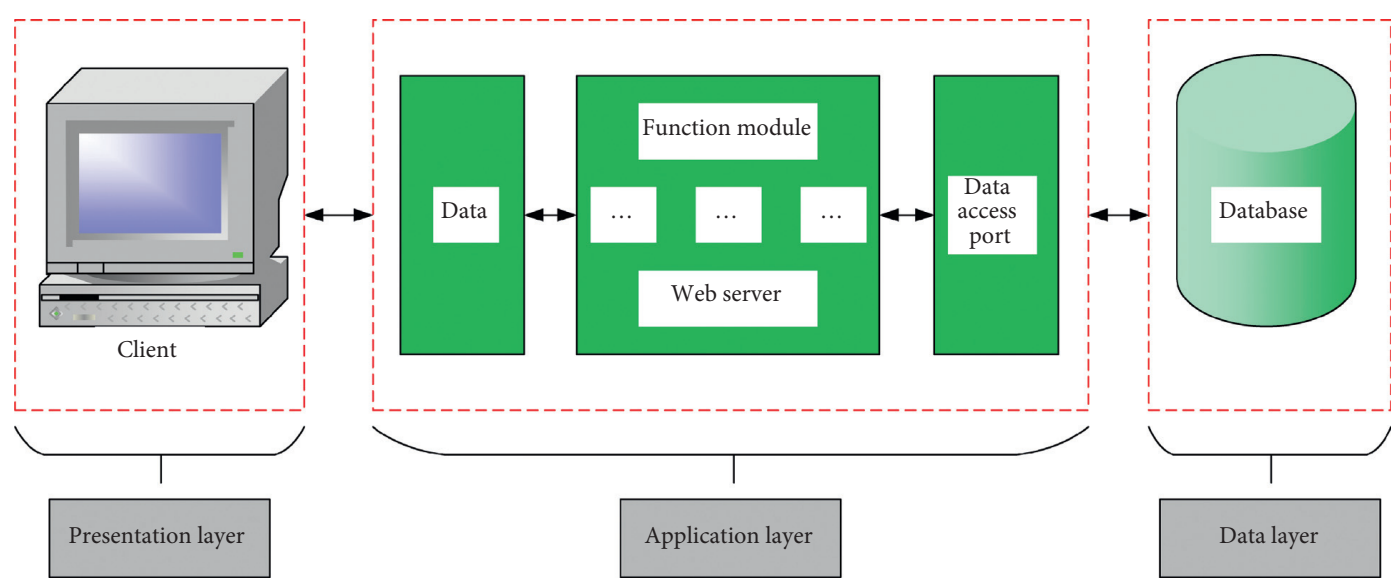

Figure 11: B/S system.

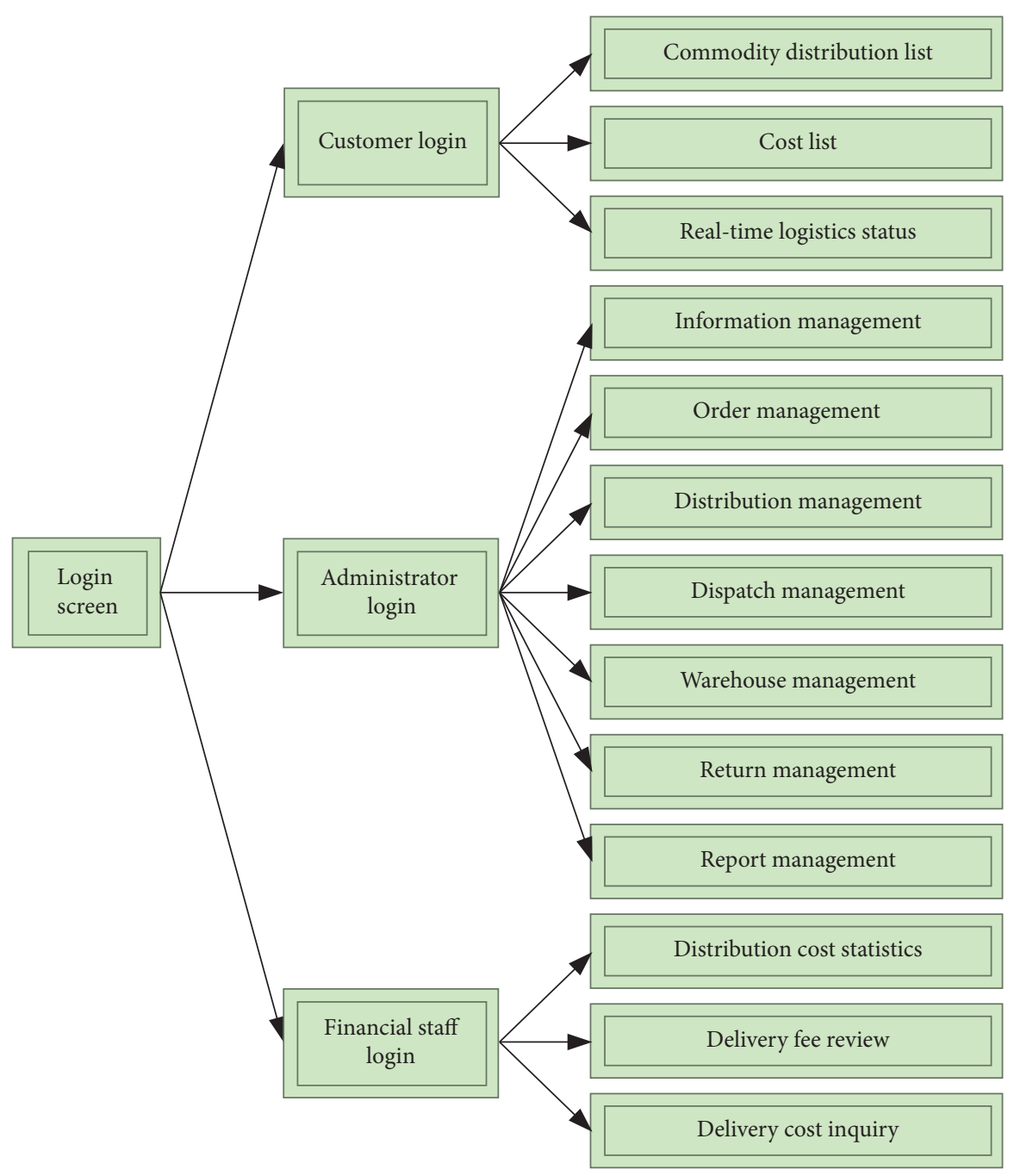

FIGURE 12: Structure of the intelligent logistics distribution management system.

3.3.2. Design of Intelligent Logistics Distribution Management System. A good environment is the premise of system design because the intelligent logistics distribution management system needs to deploy a good environment in the process. The parameters set in the system design are shown in Table 1.

In the actual verification, the same or similar logistics distribution scenarios are selected, and the traditional 
TABle 1: Parameters of the intelligent logistics distribution management system.

\begin{tabular}{lc}
\hline Name & Parameters \\
\hline Operating system & Linux 16.04 \\
Database & SQL Server2005 \\
System structure & Browser/Server \\
Development tools & Microsoft visual studio.NET 2010 \\
Technical support & .Net framework, ASP.NET, ADO.NET \\
\hline
\end{tabular}

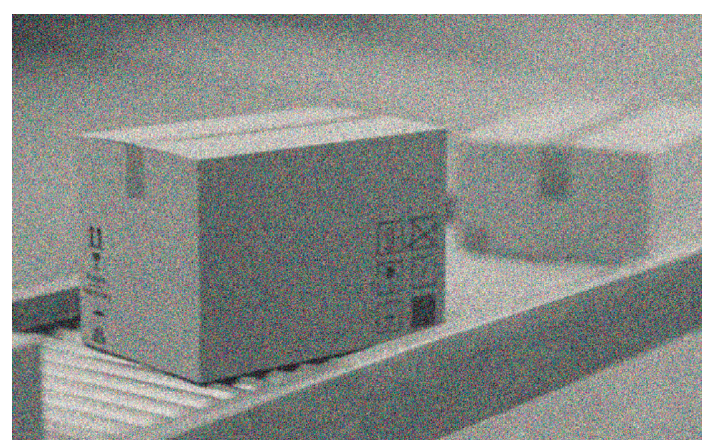

(a)

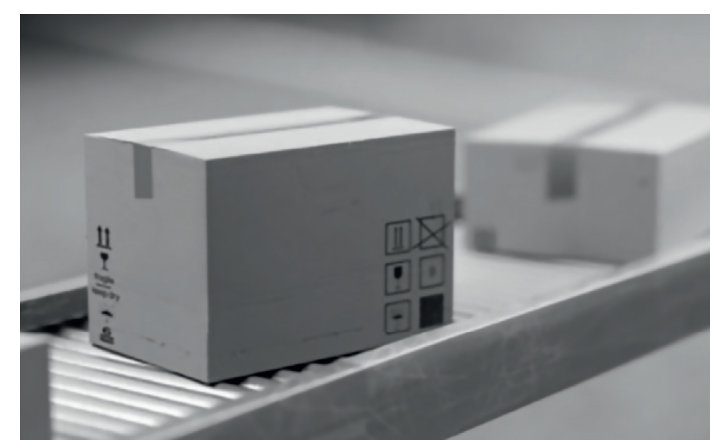

(b)

FIGURE 13: Processing results by using the median filtering optimization algorithm (a) original image; (b) the image after median filtering.

logistics distribution mode and intelligent logistics distribution management system are used for distribution activities, and the feedback results are compared and analyzed.

\section{Results}

\subsection{Influence of Visual Sensor Image Processing Technology on Target Image Processing}

4.1.1. Influence of the Filtering Optimization Algorithm on Image Processing. The original images are usually collected on roads or in an open area, so there are different kinds of noise in them. Therefore, the image filtering algorithm is used to remove the noise in the image. The processing results by using the median filtering optimization algorithm are shown in Figure 13.

Figure 13 shows that the noise in the original image can be well filtered out by using the median filtering algorithm, and the quality of the image is greatly improved in the process. That is to say, the median filtering algorithm based on visual sensors can better remove noise and remain image details. Therefore, goods can be accurately identified and distinguished to meet the requirements of logistics distribution.

4.1.2. Influence of the Image Segmentation Algorithm on Image Processing. Road images are randomly selected to be analyzed and processed in the process of logistics distribution by the target detection algorithm and the semantic segmentation algorithm. The results of different algorithms are shown in Figure 14.
Figure 14 shows that the detection algorithm only identifies road conditions, and the recognition rate is limited in identifying complex road conditions. The semantic segmentation algorithm can identify the road conditions, distinguish the details of the road conditions, and recognize any road conditions. Therefore, the semantic segmentation algorithm has obvious advantages in optimizing road conditions.

\subsection{Influence of the Intelligent Logistics Distribution Management System Based on Visual Sensor Image Processing Technology on Logistics Distribution}

4.2.1. Impact Dsof the Logistics Distribution on the Accuracy. In a similar logistics distribution scenario, the comparison results of the type, quantity, and quality of the delivered goods are shown in Figure 15.

Figure 15 shows that the intelligent logistics distribution management system based on visual sensor image processing technology is improved in types, quantity, and quality of goods compared with the traditional logistics distribution system. The average precision rate of the intelligent logistics distribution management system reaches more than $99.5 \%$, which is greatly improved compared with about $90 \%$ of the traditional logistics distribution. The quality of distribution goods also reaches $98.4 \%$, and the gap of the precision rate, the quantity, and the types of goods is narrowed.

4.2.2. Impact on Logistics Distribution Efficiency. For the size of customers, the optimal route of distribution scheduling obtained by using the model based on DTs is shown in Figure 16. 


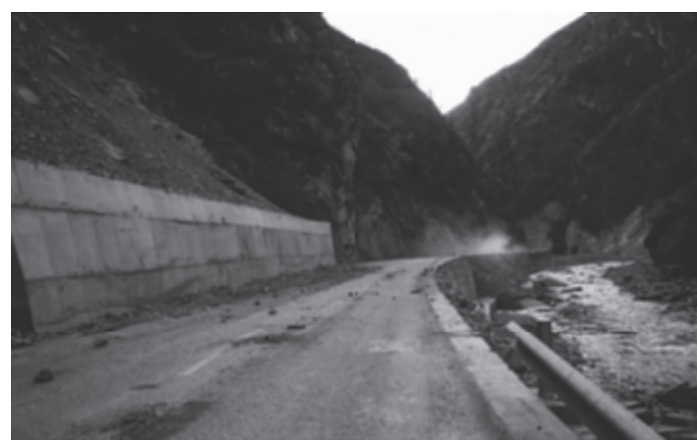

(a)

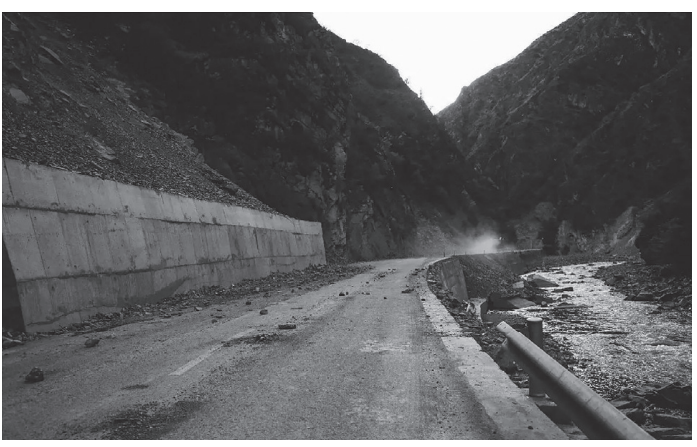

(b)

FIGURE 14: Comparison of the processing results of road images between the target detection algorithm and the semantic segmentation algorithm. (a) Analysis and processing of images by target detection algorithm; (b) analysis and processing of images by semantic segmentation algorithm.

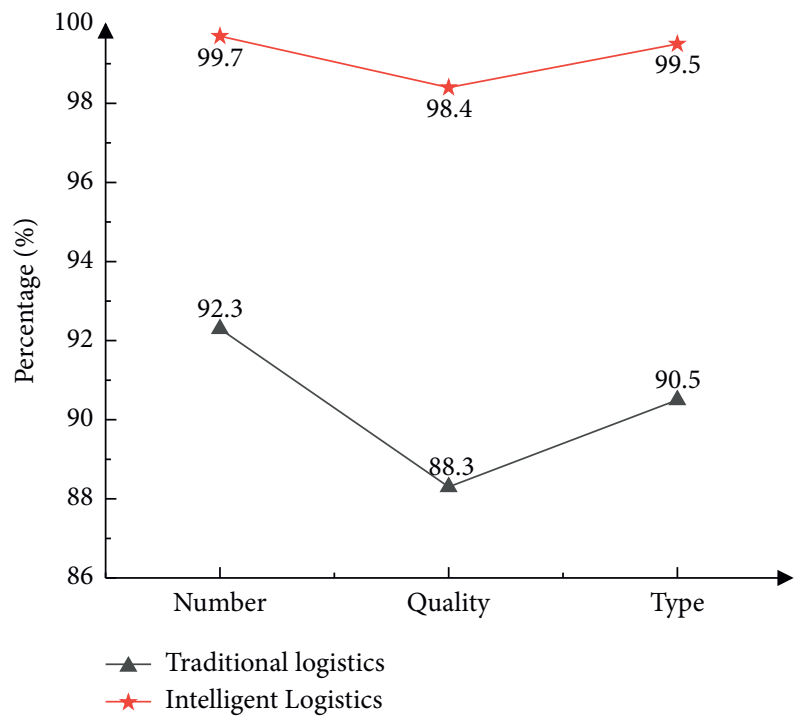

Figure 15: Comparison of the distribution accuracy.

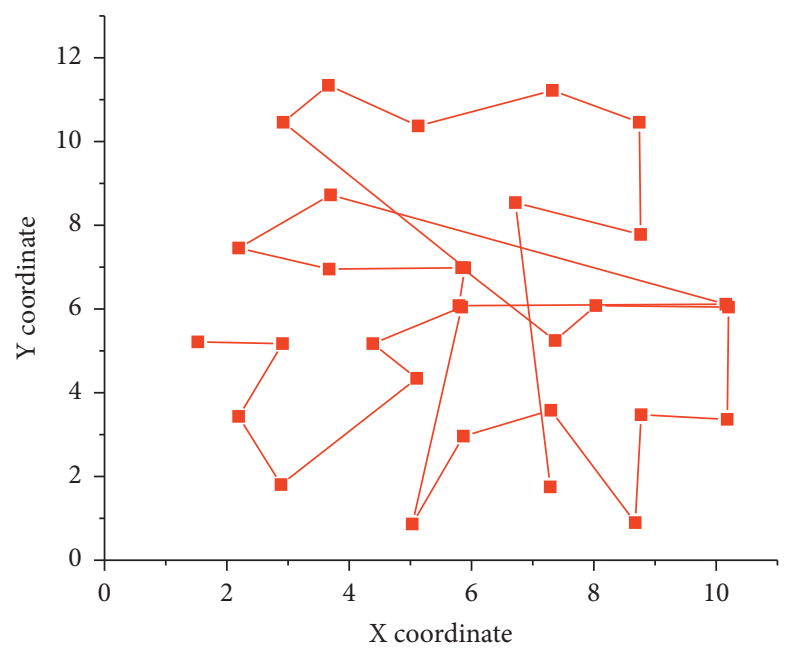

FIgURE 16: Optimal scheduling path based on digital twin. 


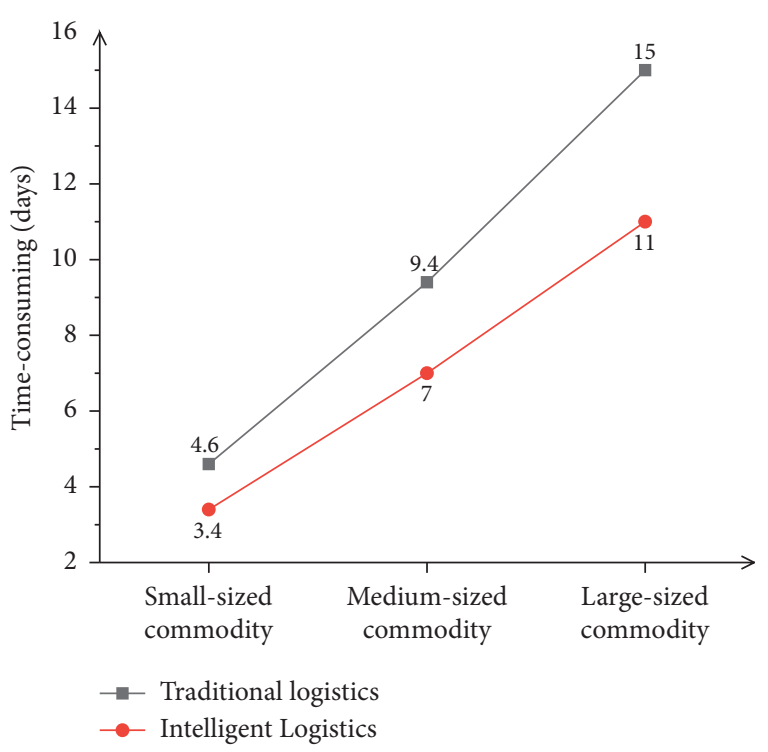

FIgURE 17: Comparison of the distribution efficiency.

Figure 16 shows that the cost of the optimized distribution route obtained is reduced by about $9.92 \%$. The optimal distribution method simulated by DTs is transmitted to the physical layer through $5 \mathrm{G}$ wireless technology. In this case, the driver receives real-time information through the vehicle system, so that the distribution route and scheme can be reasonably adjusted.

In similar logistics distribution scenarios, the distribution efficiency and cost of different goods are compared, and the comparison results are shown in Figure 17.

Figure 17 shows that when the logistics distribution scenario is consistent, the volume of the goods delivered also affects the delivery time. Compared with the delivery time of small goods, the delivery time of medium goods is doubled, and the time required for transporting large goods is about four times higher. However, compared with the traditional logistics distribution system, the distribution time of the intelligent logistics distribution management system based on visual sensor image processing technology is significantly improved. The time of transporting small goods is shortened by about 1 day, the time of transporting medium goods by about 2 days, and the time required for transporting large goods by about 4 days. It is found that the distribution efficiency is improved by about $26.5 \%$ by using the intelligent logistics distribution management system.

\section{Conclusions}

Affected by the economic system and social environment, the problems in the logistics management system are exposed. For example, the management mechanism is not clear, and the material circulation channel is not smooth; the advantages of logistics management is neglected, and scale operation and enterprise benefits cannot be achieved, making goods detained and increasing the cost. Based on machine vision, the intelligent logistics distribution management system is designed by using visual sensing image processing technology and $\mathrm{B} / \mathrm{S}$ architecture under DTs. Through the analysis and research on the visual sensor image processing technology, it is found that receipt management, distribution management, scheduling management, and return management affect logistics distribution, and it is verified by the experiments, and the visual sensor image processing technology has the characteristics of precision, intelligence, efficiency, and perfect details. The intelligent logistics distribution management system designed can effectively solve the problems existing in traditional logistics distribution management. The experimental results show that the visual sensor image processing technology can not only complete the acquisition and analysis of the target image in logistics distribution but also effectively track and monitor the target. The distribution process is simulated by the algorithm kernel, and the path and total cost of logistics distribution are obtained. Compared with the traditional method, it is verified that the distribution optimization method based on DTs can adjust the plan timely and effectively according to road and traffic conditions. The intelligent logistics distribution management system can effectively improve the efficiency of data processing, and the distribution accuracy is more than $99.5 \%$. Also, the response time is shortened by about $26.5 \%$. The research broadens the application of visual sensor image processing technology in the intelligent logistics distribution industry. The study realizes the informationization of the logistics management system and the real-time control of the whole distribution process. In this way, the real-time dynamic distribution can be transmitted to the city logistics distribution at any time, which helps management and decision-makers work out solutions in real time. However, there is a shortcoming that needs to be improved. The model constructed needs to be expanded and improved. Based on the actual needs, the system is just designed with single-line logistics as the model, and multiline logistics should be expanded and optimized.

\section{Data Availability}

The data used to support the findings of this study are available from the corresponding author upon request.

\section{Conflicts of Interest}

The authors declare that there are no conflicts of interest.

\section{References}

[1] D. C. Wang, "Construction of logistics engineering undergraduate professional curriculum system," Journal of Liaoning University of Technology (Social Science Edition), vol. 21, no. 118, pp. 118-120, 2019.

[2] Y. F. Chen, S. L. Wang, and J. Zheng, "Enterprise knowledge chain innovation under the background of green manufacturing-logistics co-evolution," Science and Technology Management Research, vol. 39, no. 9, pp. 192-196, 2019.

[3] Y. B. Wang, "Design and application of intelligent logistics warehouse management system based on Internet of things," Automation Technology and Application, vol. 39, no. 303, pp. 78-81, 2020. 
[4] H. Y. Ding, "Problems and countermeasures of rural E-commerce "last kilometer" logistics distribution," Technology and Market, vol. 27, no. 323, pp. 150-151, 2020.

[5] D. M. Lu, "Research on the optimization of rural logistics distribution system under the background of "Internet+," Technological Innovation and Productivity, vol. 312, no. 1, pp. 40-43, 2020.

[6] S. Y. Tang, "Discussion on the influence of artificial intelligence on the development of logistics industry," Modern Business Industry, vol. 42, no. 3, pp. 34-35, 2021.

[7] Y. Y. Ding, Q. Q. Gao, and X. Zhou, "Application of machine vision system in intelligent logistics conveying system," Industrial Design, vol. 165, no. 4, pp. 129-130, 2020.

[8] H. Sternberg and A. Norrman, "The Physical Internet - review, analysis and future research agenda," International Journal of Physical Distribution \& Logistics Management, vol. 47, no. 8, p. 12, 2017.

[9] T. Liu, A. Shen, X. Hu, G. Tong, and W. Gu, "The application of collaborative business intelligence technology in the hospital SPD logistics management model," Iranian Journal of Public Health, vol. 46, no. 6, pp. 744-754, 2017.

[10] D. Yang and Y. Wu, "Intelligent algorithm of vehicle routing optimization for logistics distribution," Boletin Tecnico/ Technical Bulletin, vol. 55, no. 18, pp. 512-520, 2017.

[11] C. H. Pan, L. M. Duan, and Y. S. Deng, "Research on the application of machine vision technology in automated logistics system," Journal of Kunming Metallurgical College, vol. 35, no. 152, pp. 101-106, 2019.

[12] A. Poudel, A. Meddah, and M. Witte, "Machine learning for machine vision systems," Railway Age, vol. 222, no. 7, pp. 26-27, 2021.

[13] B. Santra, A. K. Shaw, and D. P. Mukherjee, "An end-to-end annotation-free machine vision system for detection of products on the rack," Machine Vision and Applications, vol. 32, no. 3, pp. 1-13, 2021.

[14] Y. J. Han, "Exploring the design principles of robot vision system," Science \& Technology Communication, vol. 11, no. 2, pp. 115-116, 2019.

[15] H. Z. Zhao, "Research on the support system of my country's smart logistics development under the background of 'Internet+," Journal of Changchun Normal University, vol. 39, no. 366, pp. 70-72, 2020.

[16] X. M. He, "Analysis of the core competitiveness of logistics enterprises-research based on artificial intelligence," Logistics Technology, vol. 42, no. 285, pp. 19-21, 2019.

[17] X. Yang, "On the application of computer graphics and image processing technology in visual communication systems," Digital Technology and Application, vol. 37, no. 344, pp. 75-76, 2019.

[18] B. W. Sun, Z. M. Zhu, J. C. Guo et al., "Visual sensor detection algorithm and image processing flow optimization based on combined laser structured light," Journal of Tsinghua University, vol. 59, no. 6, pp. 445-452, 2019.

[19] H. B. Guo, "Weld feature extraction based on line structured light vision sensor," Electronic Technology and Software Engineering, vol. 174, no. 4, pp. 121-123, 2020.

[20] Z. X. Xie and X. M. Wang, "Small multi-AUV system formation based on vision sensor," Control and Decision, vol. 35, no. 3, pp. 60-68, 2020.

[21] L. He, "Analysis of the optimization model for selecting the shortest distribution path of intelligent logistics," Journal of Changchun Normal University, vol. 38, no. 359, pp. 76-80, 2019.
[22] H. M. Qian and Y. Y. Xie, "Research on the factors influencing the distribution efficiency of smart logistics enterprises," Logistics Engineering and Management, vol. 42, no. 307, pp. $10-11+19,2020$.

[23] S. C. Hao, "Research on the development of logistics distribution under the cloud service model," Journal of Guangzhou City Vocational College, vol. 14, no. 52, pp. 88-92, 2020.

[24] W. Yang, J. Li, and F. F. Yang, "The application of smart logistics based on Internet of Things technology in expressway service area," Transportation Enterprise Management, vol. 35, no. 360, pp. 80-82, 2020.

[25] M. Zhang, W. J. Guo, Q. Tang et al., "Design and implementation of third-party logistics management system based on B/S," Enterprise Technology and Development, vol. 455, no. 9, pp. 101-103, 2019. 